\title{
Research about Joint Distribution under Low Carbon Policy Impact on Logistics Costs
}

\author{
Li Liu, Lei Wang* \\ Beijing Wuzi University, Beijing, China \\ Email: "18162647230@163.com
}

Received 14 July 2016; accepted 21 August 2016; published 25 August 2016

Copyright (C) 2016 by authors and Scientific Research Publishing Inc.

This work is licensed under the Creative Commons Attribution International License (CC BY). http://creativecommons.org/licenses/by/4.0/

c) (i) Open Access

\begin{abstract}
This paper focuses on the new environment of logistics development in China. From the factor analysis and cost analysis, this paper respectively expounds the factors influencing the carbon cost of distribution and the influence of different low carbon policy of distribution costs, to further prove that joint distribution can effectively optimize the logistics cost. This paper presents a breakthrough in the traditional organizational barriers to make up for traditional contract deficiencies and improve joint distribution safeguard measures of regulations system, in order to provide reference for improving corporate and social logistics cost.
\end{abstract}

Keywords

Low Carbon Policy, Logistics Cost, Joint Distribution, Super Organization Management

\section{Introduction}

The Chinese government in 2009 put forward that the production of carbon dioxide emissions of gross domestic units would decrease by $40 \%-50 \%$ in 2020 compared to that in 2005 [1], and the corresponding low carbon policies were also introduced. Compared with the developed countries, the problems of low efficiency of Chinese logistics and logistics costs have been serious, especially the green logistics cost is much higher. Along with the advancement of global low carbon measures, the logistics industry in China as a large energy consumption industry should practice strict energy conservation and emissions reduction is the trend of the Times.

The past decade, Chinese transportation industry is one of the fastest growing energy consumptions of the industry, which consumes more than 50\% consumption of energy, resulting in nearly $70 \%$ of the carbon emissions [2]. Practical experience shows that in developed countries, joint distribution is a way to improve vehicle rate and reduce the load rate, thereby reducing the traffic distribution mode, the use of energy and the carbon emis-

${ }^{*}$ Corresponding author. 
sions compared with traditional distribution model. The advantage is obvious. Therefore under the guidance of low carbon policy, the development of joint distribution has a great potential.

\section{The Analysis of Factors Affecting the Cost of Carbon Emission Distribution}

For businesses, the carbon cost is decided by the amount of carbon emissions to reduce costs, it is necessary to reduce carbon emissions. And factors affecting the distribution activities in carbon emissions are mainly delivery mileage and delivery shipments; in general, delivery miles farther load more and more carbon emissions. The joint distribution through the integration of resources distribution and the consolidation of distribution mileage reduces the cost of carbon emissions. Concrete evidence is as follows:

The regression analysis based on data gathered can get distribution of carbon emissions and distribution of binary linear distance and load function, that is

$$
f(d, x)=a d+b(Q+x)+c
$$

where $d$ is driving distance, $Q$ is vehicle weight, $x$ is cargo traffic, $a, b, c$ are constants.

Assuming that the maximum load for vehicles is $Q^{*}$, and the full carbon emission for unit distance is:

$$
f_{1}=a+b\left(Q+Q^{*}\right)+c
$$

The no-live load unit distance of carbon emissions is

$$
f_{2}=a+b Q+c
$$

Combining (2) and (3)

$$
b=\left(f_{1}-f_{2}\right) / Q^{*}
$$

A distribution of cargo is bound, and $x$ is fixed at a certain value, and the formula (1) can be

$$
f(d, x)=a d+w
$$

Among

$$
w=\left[(Q+x)\left(f_{1}-f_{2}\right)\right] / Q^{*}+c
$$

In the distribution process, the carbon emissions generated by the transport cost is

$$
G=e g(a+w) d^{*}
$$

Among them, the emission factor $e, g$ for carbon emission factor, $G$ for the distribution of carbon emissions costs, and $d^{*}$ for the length of distribution lines, it can be considered $d^{*}=d$.

By equation (7), distribution of cost and distribution are directly related to carbon emissions. When the shipping lines established, vehicle fuel consumption will increase as delivery volume increased slightly, but have not increased much, sometimes ignored this increase [3]. Therefore, it can be argued that for determining the route for the distribution of, and increase the vehicle's weight does not bring about increases in the cost of carbon emissions.

In an ideal situation, assuming $n$ enterprises have distribution business on the same route, the amount of each distribution is $p_{1}, p_{2}, \cdots, p_{n}$, and the distribution line length is $d$. From the foregoing analysis, if the enterprise uses individual distribution, the cost of carbon emissions is $n G$. Joint distribution of total amount of distribution is equal to the dispersion of a separate distribution, and taken together matching the number of vehicles in use is far less than the former, vehicle's total length of distribution lines is far less than the former, the resulting carbon emissions costs would have fallen sharply.

\section{Significance of Different Low-Carbon Policies of Joint Distribution Cost Reduction}

\subsection{Under the Mandatory Emissions Limits, Increase Turnover and Reduce Unit Costs}

Mandatory emission policies show that the government sets stringent emission limits, if over the limits, the en- 
terprises need to pay a fine, or even need to stop its distribution business. This is a very serious policy and a strong binding.

Under this policy, the carbon emission allowance of is enterprises dispersed, which limits the expansion of turnover, so it is also very difficult to make full use of quotas spare cargo. Taking joint distribution can obtain greater carbon emission quota and can reduce the limit of turnover by limiting quota. At the same time, higher emission quota also helps the arrangement of each distribution business, optimizes the integration of turnover and achieves fully utilized emission limits.

\subsection{Rationally Utilize Tax Planning, Improve Effective Delivery Mileage, Reduce Total Costs}

Carbon tax policy is according to the emissions and in accordance with a certain tax to charge emissions tax. The policy does not strictly limit to maximum amount of emissions of the enterprises, but charges tax according to its all emissions.

At present the country doesn't have a clear way of carbon taxes, but scholars believe that steps should be taken tax [4]. With the increase of the tax rate, the proportion of the cost of carbon emissions accounted for total distribution costs gradually increases. Reducing the distribution mileage and carbon emissions to ensure the profitability has become the main target of distribution. A common distribution, improves effective delivery mileage, reduces carbon emissions, thereby further reducing logistics costs.

\subsection{Flexibly Use Trade Policy, and Share Logistics Resources to Achieve Value-Added Logistics}

Carbon trading policy, that is treat carbon dioxide emissions as a commodity, companies were assigned to certain emission allowances, if enterprise emissions exceed a fixed degree will need to purchase a certain amount of emissions, and vice versa can sell out the carbon emissions credits. Based on the foregoing analysis, the joint distribution by increasing turnover and effective delivery mileage can make the carbon emission targets be possible and reasonable overflow.

Under the policy, the cost of carbon emissions may also be converted into new profit point. We need to adopt a joint distribution and optimize business operations in order to get more reasonable overflow and finally achieve a reasonable distribution of carbon emissions resources on the supply chain.

\section{To Discuss Joint Distribution Mode, the Effective Operation of the Safeguard Measures}

The concept of distribution and joint distribution in the late 80's has been introduced into China, but compared to the sound development of foreign joint distribution, progress in our joint distribution developed slowly in past 20 years and had less successful experience. And the current low carbon policy is carried out based on the context of globalization, when the external environment is more complex, synergy level is higher, therefore, it needs the government and enterprises to take corresponding measures to promote the construction of joint distribution system and effective operation.

\subsection{Breakthrough the Traditional Organizational Barriers and Promote the Realization of the Function of the Third Party Logistics Enterprise}

Super organization is a group enterprise, which has vertical correlation, but legally separates, and shares common interests in separate decisions [5]. Super group can effectively break down barriers between organizations, fully integrate enterprises' resources, and improve operational efficiency.

Low-carbon policies, common factors affecting the distribution of increased business risk has increased and the traditional organizational forms are difficult to adapt to the complex internal and external environment, need more advanced forms of joint distribution organization to ensure sound operation. Jointly invest in independent third-party joint distribution companies, namely third-party joint distribution organization, broke away from the traditional joint distribution mode of interaction to achieve multiple management system of checks and balances, the full realization of the enterprise's hyper-function, shareholder accountability better able to bear the risk. From a long-term perspective, and jointly invest in the establishment of an independent third-party development of joint distribution company is the joint distribution of the mainstream. 


\subsection{Make up for the Lack of Traditional Contracts, Build up a Good Common Delivery Framework for Effective Implementation of Contracts}

Traditional logistics enterprise contract is "one to one" contract, under this contract, and not only be a waste of social resources, and supply chain resources integration cannot be achieved, raising the cost of logistics. Joint distribution is the basic starting point of distribution between enterprise resources integration, achieving further increases in efficiency, smooth running of joint distribution on the premise that resource sharing, you must break through the traditional contractual restrictions.

Third-party logistics and distribution contracts were on a higher level of resource integration contract, break the barriers to sharing of resources, make full use of social resources, to achieve "one to many" service for common distribution services to further enhance the ability of. For the new contract, assessment criteria focused not only on the cost evaluation of single, need to fully consider the service contract level, as the increased realization of joint distribution of the contract service.

At present, the joint distribution of third party logistics contract main difficulty lies in the establishment of inter-organizational accounting system across the enterprise, which is reluctant to face, but unable to avoid problems. And under the low carbon policy, cross-organizational carbon cost is the most difficult problem to solve. Based on the noted above, under the third-party joint distribution organization, how to play a super organization, breaking down organizational barriers are the key.

\subsection{Improve the Regulatory System to Provide Good Environment for the Operation of the Organization and Management}

Good operation environment of joint distribution needs perfect system of laws and regulations as a guarantee. There is no doubt that the contract law and property law as the main logistics policy system for guidance and protection in the joint distribution operations played a huge role. However, at present on the joint distribution of the relevant policies and regulations there are still some problems and deficiencies. First, default penalties is light, and low cost of default affects the reliability of the contract; second, the comprehensive information security regulations are lack and customer information leakage as well as the operational information and other problems occurs during the joint distribution; third, some important systems need to be identified and specifically regulated by laws and policies, such as third party liability system and punishment system.

To improve the default provisions regulation in the Contract Law and Property Law, the penalties for default should be increased; for the third-party joint distribution, relying on the existing Personal Information Protection Guide in Public and Commercial Service Information Systems of Information Security Technology, related policies to protect customer information should be published to further specify the system and regulations of thirdparty joint distribution, clear the third party liability, and implement the penalties system. At present, China's carbon emissions legal system is not perfect, and there is no targeted regulatory to disputes which generate in carbon emissions joint distribution [6], so the introduction of relevant policies and regulations under the context of low- carbon policies is imminent.

\section{Conclusions}

In the background of low carbon development and to reduce logistics cost, the joint distribution as the experience of operation mode has certain development, because it can effectively reduce carbon emissions, optimize the logistics cost, and coruscate new vitality. For enterprises and even the whole society logistics, to develop joint distribution largely has an underestimated significance.

Lower logistics cost is an eternal topic, and has constantly arisen new problems. Under the new policy, we need to review, and constantly perfect the relevant analysis and elements of process reengineering and cost. Therefore, related research is necessary to continue.

\section{References}

[1] Yang, J. and Lu, W. (2014) Low Carbon Policy Study on Capacity of Location and Distribution Problems. Management Science in China, 22, 51-60.

[2] Liao, W. (2014) Consider Joint Optimization of Vehicle Routing Problem in Distribution and Energy Consumption. Southwest Jiaotong University, Leshan. 
[3] Lu, F. (2011) Joint Distribution Mode of Operation and Cost-Sharing Research. Jilin University, Changchun.

[4] Yang, Y.W. and Lin, S.F. (2011) Carbon Tax and Carbon Trading under the Condition of Logistics Distribution Center Location Model. Logistics Engineering and Management, 33, 119-122.

[5] Ballou, R.H. (2006) Logistics Management-Supply Chain Planning, Organization and Control (Xiaodong Wang, Translate). Mechanical Industry Publishing House, Beijing.

[6] Li, Y.F. and Wu, Y.C. (2011) Legal and Policy Framework Low-Carbon Economy in China: Current Situation, Problems and Improvement. Journal of China University of Geosciences (Social Science Edition), 11, 18-23.

\section{Submit or recommend next manuscript to SCIRP and we will provide best service for you:}

Accepting pre-submission inquiries through Email, Facebook, LinkedIn, Twitter, etc.

A wide selection of journals (inclusive of 9 subjects, more than 200 journals)

Providing 24-hour high-quality service

User-friendly online submission system

Fair and swift peer-review system

Efficient typesetting and proofreading procedure

Display of the result of downloads and visits, as well as the number of cited articles

Maximum dissemination of your research work

Submit your manuscript at: http://papersubmission.scirp.org/ 